\title{
Supplementary Virtual - Class System as a Possible Frontier for Bridging the Grades Gap between Top Tier and Low Tier High Schools in Ghana
}

\author{
Ampadu Seth $^{1, *}$, Bernice Okpatah ${ }^{2}$, Amoako Richard ${ }^{1}$, Azamela John Coffie $^{3}$, Antwi Owusu Justice ${ }^{3}$ \\ ${ }^{1}$ Hefei University of Technology \\ ${ }^{2}$ University of Cape Coast \\ ${ }^{3}$ University of Electronic Science and Technology of China \\ *Corresponding author: sethKampadu@yahoo.com
}

Received November 17, 2018; Revised December 24, 2018; Accepted January 04, 2019

\begin{abstract}
This paper tries to create the awareness of VLE as a new supplementary teaching technology frontier which could be utilize to bridge the grading gap between rural and urban students. The benefits associate with VLE technology is enormous, not only can it enhance academic performance of rural schools and students in Ghana but also could enrich students and teachers learning this experience if it is properly and effectively adopted and monitored. This could automatically result in students achieving good grades. Various Observations have been carried out to estimate it viability and it shows students and schools that adopt this technology benefited immensely from this approach, although it come with some challenges. VLE demand users and operators to have ICT knowledge and skills which may not be readily available. With proper planning, infrastructure, skills, resources and effective monitoring system, VLC could be a major technology to bridge the gap between TTS and LTS in Ghana Education System.
\end{abstract}

Keywords: VLE, VLC, Rural and Urban grades, Education, LTS, TTS

Cite This Article: Ampadu Seth, Bernice Okpatah, Amoako Richard, Azamela John Coffie, and Antwi Owusu Justice, "Supplementary Virtual - Class System as a Possible Frontier for Bridging the Grades Gap between Top Tier and Low Tier High Schools in Ghana.” American Journal of Educational Research, vol. 7, no. 1 (2019): 6-11. doi: 10.12691/education-7-1-2.

\section{Introduction}

For many years it has been the problem that remains unsolved, the grade disparity of urban and rural schools in Ghana. Government and other stakeholders have pursued various programs and agendas to curb the situation but to no avail. Various reasons were attributed to be the causative factor for this disparity and measures were put in place with the view of handling this issue. Despite these efforts the disparity continues to widen. This phenomenon could be found in most rural areas around the world. With the introduction of VLE some research finding concluded that the use of VLE technology can improve the performance and grades of students, amplifies learning approach and attitude of student [1,2,3]. It has also emerge that a combination of traditional and VLE with sturdy instructor can result in a desirable outcome in terms of satisfaction and learning accomplishment [4]. This is enough proof that Ghana Education Service can employ such mechanism or technology to ascertain it viability in the Ghanaian Education Sector in the quest of bridging the grades disparity gap between Urban and Rural School and at the same time provides equal opportunities for rural schools and students.
Education is known to be a key to fighting poverty and other social vices that slows the development of a country as it seeks to develop the moral, competence, abilities, technical competence, conduct or attitude of a person with the aim of making him or her productive in a societal set [5]. Education provides the basic skills need for survival and it is one of the medium through which a nation's goals could be achieved [6]. The status of a school has a significant influence on the final results of a student as confirmed by Khattri, Riley, Kevin \& Kane in their research which stipulates that students who attend poor schools tends to perform below average as compared to those who are enrolled in urban or less deprived schools [7]. Some African countries have seen the importance of such platform and are investing massively in this technology with the view of boosting their career [8] as it has been observed globally that students interest in VLE is high [9] hence the need for education players to capitalized on.

A strong educational system puts in place mechanisms, strategies, tools and technologies for students to reach their full potential and this should be in the heart of every country, entity, corporation, institutes and government [10]. ICT is constantly evolving and their utilization in the education sector cannot be underestimated [10]. The traditional class setting where a teacher and students 
comes face-to-face in a physical context is still practicable but the emergence of wireless technologies, virtual technologies, e-learning and other modern educational technologies has made education accessible irrespective of one's location [11]. As confirmed by White, Susan C, Glickman, Theodore S, technologies such as virtual learning is a positive platform for delivering academic courses or programs in a sophisticated manner [12]. A research conducted by J. Lowicki-Zucca Matthew E, Amir H, Nino P \& Jafar U, revealed that youth demands quality education and good grades irrespective of their location [13]. In this regard, Bruce and IIonan stated that one of the many means of solving and improving grades of students is through Virtual Learning Environment [14]. They again stated that Virtual learning environment is much cheaper than Physical Learning Environment, however, lacks physical contact, the outcome on students achievement is always positive [14]. Other researchers corroborate this with findings that virtual learning is productive as it provide a platform for students to engage in interactive activities relating to their field of study and also creates a bond between users of such educational technology [15]. Most students also rely on Virtual Learning class to access learning materials that are not available to them immediately.

\section{Literature Review}

\subsection{Challenges in Rural Education}

One of the many challenges facing Ghana in it education sector is the grade disparity of students from Urban and rural areas. From the beginning of time, urban students lead the best grade in the country's Exams conducted by the West African exams council (WAEC). This disparity has been linked to economic differences which has led to unequal sharing of educational resources [16]. Despite these phenomenon, students from Urban and Rural schools follow the same curricular, developed by the curriculum and research division of the Ghana Education Service, sit for the same exams conducted by WAEC [16]. Failure in this exam denies students the chance to pursue a Higher Education. The economic burden on poverty driven parents blocks the chances of students to get access to better High school education. Although there is the existence of a computerized placement system that automatically places Junior High School students into Senior High School, majority of good students that find themselves in schools located in rural areas still performs below their capacity. This is premised upon the fact that rural schools lack the requisite educational resources and materials to educate their students to rub shoulders with urban schools in terms of academic achievements, as the status of such schools have an insightful sway on their academic performance [16]. The International Labor Organization added their voice into this issue in their 2016 report on Rural Teachers in Africa, which suggested that teachers should try and go beyond the economic burden in rural areas [17]. Virtual Learning class could be a step in a right direction to mitigate these and many issues related to disparities between Urban and Rural schools. There is also the issue of posting of teachers to rural areas, as it is mostly evidence, a good number of teachers refuse or feel reluctant to go to rural areas. These has widen the disparity to the detriment of student in rural settings [17].

\subsection{Virtual Learning Class-VLC}

Virtual learning class is a component of a Virtual learning environment where student receives program or course instructions through a virtual class online [18]. It is also known to be the technology that viaduct the gap created when teachers and students are detach in time and space [19]. Aside this, it focuses on student learning activities, content guidance and facilitate remote interaction between teachers and students. Virtual learning should be designed in way to support other incorporated tools necessary for a fruitful virtual learning outcome $[18,20]$, these tools may include:

- Management tool

- Students/Schools trail

- Access and assessment of resources and performances

A combination of these tools facilitates communication between in-house teachers, remote teachers and students as it opens an avenue for virtual chat or real-time communication which in turn will influence virtual results and enhances ample level of development in rural schools grade context. It's even possible to add a VLC Library to this system [21]. Failure to bring these resource together for proper deployment may result in ineffective interaction contents [22]. This may have a negative repercussion on the grades and performance of Students. VLE requires effective coordination work from VLEP starting from the onset to the final stage [23].

\subsection{The Benefits of Virtual Learning}

Technology comes with it benefits and VLE is no exception. VLE has numerous advantages over traditional system of learning where students and teachers had to be physically present. Some of the benefits of VLE include the following:

It significantly reduces the saddle on teachers as teachers becomes facilitators whereas students survey and learn in a virtual world [23,24]. As it is linked to Educational curricular, it is more student-focused and very objective-oriented than traditional learning environment [23]. It is also known to be accessible, communicative and interactive than traditional learning. VLE again give students the chance to revisit, rewind, freeze or fast-forward a class they missed as VLE keeps a recording of the class in it video database [25]. It disadvantage is the inability to cater for the physical needs of students as it does not take into consideration of those needs and it adoption could be complex as it require stakeholders to provide the essential infrastructure and teachers to build up a multiplicity Information Technology Skills which might not be readily available [26] Others also suggested that instruction complexity, lack of proper organization, poor planning, poor stakeholders support, constant changing of roles, unstable network coupled with improper planning are some of the difficulties and challenges facing VLE [26].

Despite these challenges, there is evidence that VLE has the potential to enhance students' performance 
academically if students or schools approach and adopt it with clear objective [27,28,29,30]. In this regard, stakeholders support should be strong and as it will be the stepping stone for it adoptability, utilization and more importantly, influence the interest of student to patronize [31].

\subsection{Virtual Learning Environment Players (VLEP) and their Roles}

The collaborative effort of various players are needed for the effective implementation and success of Virtual Learning class as stipulated by Caudle 2013 [32]. A vivid instruction on learning and teaching facilitation enhances teacher students interactions. Availability of Instructors to provide immediate feedback also enhances interaction in VLE [33] VLE needs players such as:

- Subject facilitators, who are responsible for persuade students to get involve.

- Subject professional/specialist/expert

- Subject Designer (curricular development team)

- VLE materials Managers responsible for VLE course material such as recording videos, lectures, and other actions to satisfy students with diverse learning skills.

- The services of course or curricular developers are very important as it forms the basics of what to be taught.

- Network providers are also needed as they provide network access for VLE

- Examiners are required in VL environment as they provide questions to ensure learning reflect or are in-line with the curricular

- Other players needed are counselor, Moderators, Explorers, Technicians and Repositories.

The presence of the above players can ensure the smooth operation and success of a supplementary Virtual Learning Class [33,34,35].

Table 1. Traditional study cycle

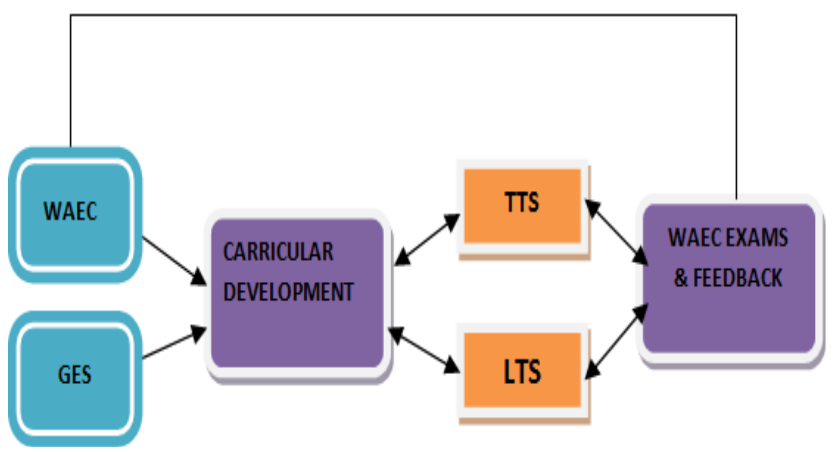

The current examination set is that, Curricular is developed for Schools (Kindergarten, Nursery, Primary Schools and Senior High Schools), this curricular is followed by both Top Tier and Low Tier schools in the country irrespective of location. In the final year at the High School, a one paper examination is conducted by the West African Examination Council to grade students' performance and it also determines the academic journey of students to Higher Education.

In most cases, Top Tier schools come on top in terms of grades and admission into the various universities in the country. The current system does not provide an avenue for Low Tier schools to have access to the manner, atmosphere and skills in which lessons are disseminated although they sit for and follows the same curricular. The academic career path of rural and urban students depends on WAEC final exams as it holds the key to Higher Education.

\section{The Proposed Teaching/Study Cycle}

The proposed cycles do not only contain the already existing model but also link VLC framework cycle. This model is different from the already existing traditional model as it create avenue for LTS to connect and view lesson and class activities of TTS. The proposed process involves the following:

\subsection{Curricular Development}

The system proposed that the development of Academic Curricular is the sole responsibility of coordination between GES and WAEC. The curricular developed are deployed to the various schools in Ghana. At this stage, a curricular or a course outline is developed by these stakeholders base on areas for the final exams to be taken by students from TTS and LTS. In a nutshell, the curricular are made available to TTS and LTS through the various channels thus the regional to district Education managerial teams, who them forward it with the requisite directives to the schools.

\subsection{Lessons Feed, Recording and Live Streaming}

At this stage, the curricular developed are made available to the various schools. School teachers on the related subjects are require to follow the curricular to the core, in addition to this, there is VLC platform where the class proceeding of all TTS are live-stream and recorded in a subject Video Bank. In this case LTS are either:

- Require to watch the lesson and ask a real-time questions and answer questions respectively, in this case they become part of TTS. The LTS teacher in this case has the responsibility to guide students and further explain issues and question raised in the lesson.

- Since the proceedings are recorded and keep in a Subject Video Bank, LTS could revisit the video and watch again, in case certain explanations were not clear to them.

- LTS have the choice to select TTS lessons they want to watch.

The VLC platform gives LTS multiple choice and a huge virtual teachers options in addition to their in-house teacher.

\subsection{Security Issue}

In order to ensure security, LTS's are required to seek Approval from GES through a portal in the VLC system. Records of approval, login time, date, and subject viewed, TTS connected, Teachers name, Study tracks are recorded in the SVB. In addition a pre-permission could be sort from GES before a class begins. 
Table 2. Proposed VLC Cycle (Simple version)

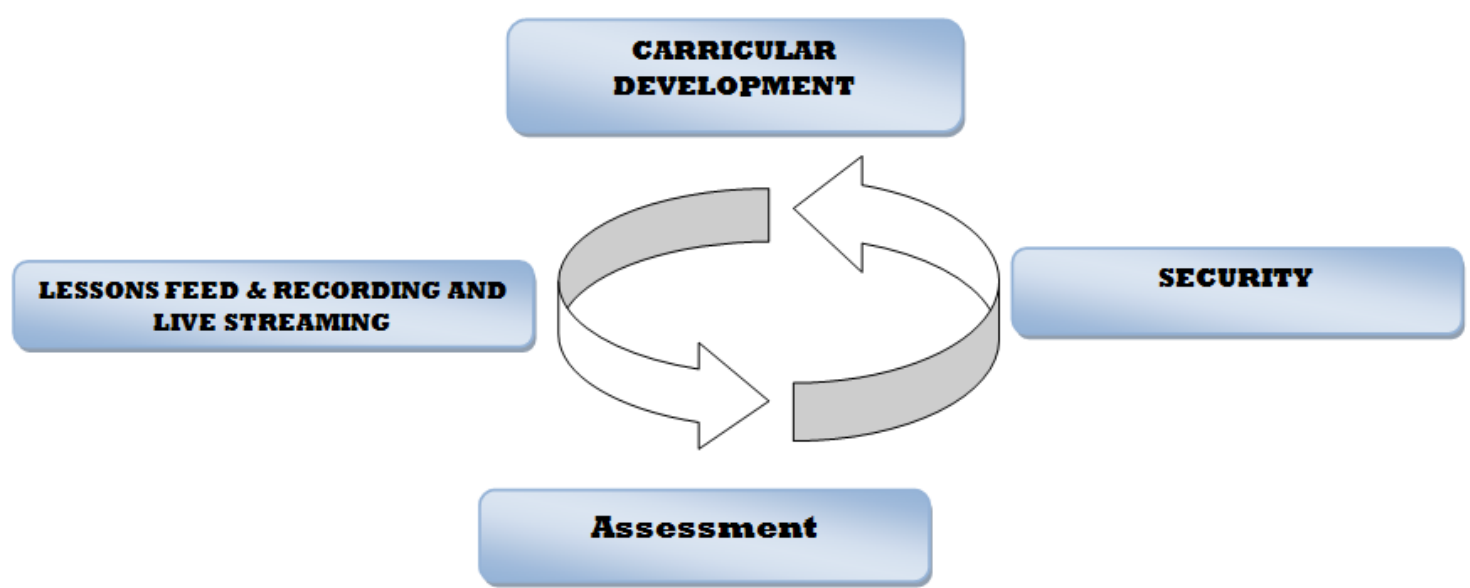

Table 3. Explanatory VLC cycle

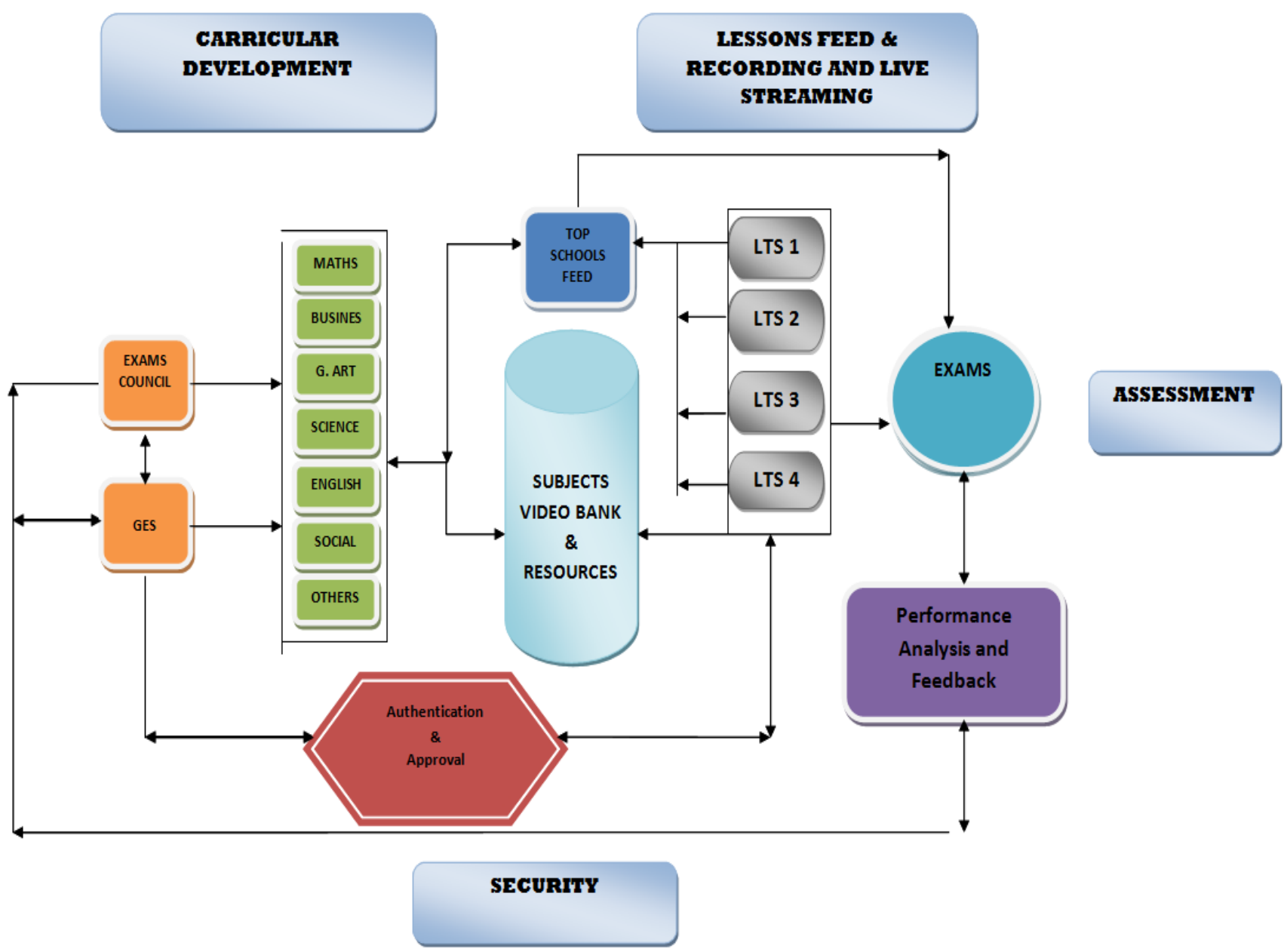

Assessment: At the assessment stage, WAEC organizes their usual exams, taking into consideration the curricular developed and the course outline as stated in the Development stage. After the examination a performance analysis is made by Stakeholders thus WAEC and GES individually, a feedback is given to both TTS and LTS. The performance of LTS is compared with TTS, taken into accounts, the VLC Lesson taken by those LTS; this will enable Stakeholder to actually know the correlation between VLC lessons taken by LTS and Performance in WAEC examination. GES can also carry out their own performance analysis of TTS and LTS and make the necessary recommendation as applicable. This will help to know the challenges in VLC implementation and make the necessary adjustment.

\section{Implication}

Various researches has been carried out in recent years which suggested that blending VLE tools in teaching process promotes students interaction and increases learning satisfaction among students [36]. Merging technology do not only makes learning interesting but also has the potential to enhance deep learning approach [37]. The suggested process does not give a clear comparative result 
of final grades between Urban and Rural Schools but rather suggest a mean of which GES can improve the grades of rural students by making resources, direct and indirect video classes/lessons of TTS available to LTS, as it has the latent of enhancing their grades and also encourage them to be dynamic and vibrant learners [26].

In order to get the most out of this approach, lessons and academic resources which are tailored to the related subject curricular, including Teachers should be monitored closely as instructional quality process is of major concern when it comes to VLE [38,39].

As this could be a new learning approach area, it is important to engage all stakeholders in ICT training. There should also be collaboration between educational stakeholders and Network Service Providers as all transmission depend on their ability to provide stable wireless transmission of lessons. Schools in rural areas also need to be connected or have access to a wireless thus they should be internet-enabled before this technology could be accessed. There is also the need for stakeholders to take a critical look at security issues on this platform.

\section{Future Study}

Studies and research need to be carried out in the area of VLE management, security, accepted VLE resources, monitoring of activities as this article only suggest VLE ideology.

\section{Recommendation and Conclusion}

The main purpose of this paper is to bring forth, a new learning perspective which could go a long way to enhance the grades and academic performance of students and schools captured or labeled as LTS. By instituting this technology, students from LTS will also have a firsthand feeling of what goes on in TTS as they will have the chance to be part of such lessons, watch and ask questions on real-time and have their questions answered. As lessons are recorded and kept in subjects' video bank, LTS and TTS have the chance to revisit lessons.

We are in a modern world and it is up to stakeholders to make use of all educational technologies available. The development of a country does not only depend on it wealth but also their ability to develop it Human Resources to meet the opportunities, changes and problems as it comes and this could only be achieved through proper quality education. The institution of VLE platform is therefore recommended as a model for enhancing learning and teaching in GES system as it provides a unique podium for enhancing Students learning experience and performance.

\section{Abbreviations}

VLE - Virtual Learning Environment

VLC- Virtual Learning Class

TTS- Top Tier Schools

LTS- Low Tier Schools

WAEC- West Africa Examination Council
GES- Ghana Education Service

VLEP- Virtual Learning Environment Players

VLCR- Virtual Learning Class Records

SVB - Subjects Video Bank

ICT - Information Communication Technology

\section{References}

[1] M. Alavi, "Computer-mediated collaborative learning: An empirical evaluation.,” MIS Q., vol. 18, no. 2, 1994.

[2] R. H. Maki, W. Maki, M. Patterson, and P. Whittaker, "Learning and Satisfaction in OnLine Versus Lecture Courses. Behavior Research Methods, Instruments and Computers.” vol. 32(2), pp. 230-23, 2000.

[3] J. G. Schutte, Virtual Teaching in Higher Education: The New Intellectual Superhighway or Just Another Traffic Jam?, California State University, Northridge, CA. 1997.

[4] T. Enhanced, L. Ijtel, and A. Number, "Communi Ties: Success Factors and Challenges. In: International Journal of Virtual learning communi Ties: success factors and challenges René Wegener * and Jan Marco Leimeister," Int. J. Technol. Enhanc. Learn., vol. 4, no. 2012, pp. 383-397, 2012.

[5] A. Dorleku, "Teaching and learning in border towns: A study of four junior high schools along the Ghana-Togo Border, Kwame Nkrumah University of Science and Technol,” 2013.

[6] O. R. Aremu and B. O. Sokan, "A multi-causal evaluation of academic performance of Nigeria learners: Issues and implications for national development,” Department of Guidance and Counselling, University of Ibadan, Nigeria., 2003.

[7] N. Khattri, K. W. Riley, and M. B. Kane, "Students At Risk in Poor , Rural Areas: A Review of the Research,” J. ofResearch Rural Educ., vol. 13, no. 2, pp. 79-100, 1997.

[8] Docebo, "E-Learning Market Trends \& Forecast 2014 - 2016 Report,” 2016.

[9] T. Can, "The Use Of 3d Virtual Learning Environments In Training Foreign Language Pre-Service Teachers,” Turkish Online J. Distance Educ., vol. 16, no. 4(9), pp. 114-124, 2015.

[10] A. Vassiliou, "Key Data on Learning and Innovation through ICT at School in Europe 2011,” 2011.

[11] M. Hampson, A. Patton, and S. Leonie, "10 ideas for 21st century education," 2015.

[12] S. C. White and T. S. Glickman, "Implications for the Future," wiley Inter Sci., no. 137, pp. 97-106, 2007.

[13] L.-Z. Jane, E. Matthew, H. Amir, P. Nino, and U. Jafar, "Demand for Education Innovation Adolescent and youth perspectives on education quality in the CEECIS Region."

[14] B. Kneale and I. Box, "A Virtual Learning Environment for RealWorld Networking Problems with Providing a Physical Network Lack of Funds,” J. Inf. Sci., no. June, 2003.

[15] R. Cosgrave, A. Rísquez, T. Logan-phelan, T. Farrelly, E. Costello, and M. Palmer, "Usage And Uptake Of Virtual Learning Environments In Ireland: Findings From A Multi Institutional Study,” All Irel. J. Teach. Learn. High. Educ., vol. 3, no. 1, pp. 1-14, 2011.

[16] N. A. A. Opoku-asare and A. O. Siaw, "Rural - Urban Disparity in Students' Academic Performance in Visual Arts Education: Evidence From Six Senior High Schools in Kumasi, Ghana," SAGE Open, 2015.

[17] ILO, "Rural teachers in Africa: A report for ILO Rural teachers in Africa: A report for ILO,” 2016.

[18] V. L. Environments and C. Design, "Effective Use of VLEs: Introduction to VLEs Introduction to VLEs," JISC, pp. 1-44, 2015.

[19] P. W. Stonebraker and J. E. Hazeltine, "Virtual learning effectiveness An examination of the process," Emerald Res., vol. 11, no. 3, pp. 209-225, 2004.

[20] S. Cassidy, "Virtual Learning Environments as Mediating Factors in Student Satisfaction with Teaching and Learning in Higher Education,” J. Curric. Teach., vol. 5, no. 1, pp. 113-123, 2016.

[21] American Association of University Adminstrators, "The Journal of Higher Education Management," J. High. Educ. Manag., vol. 27, no. 1, 2012.

[22] S. Penjor, "Predicting Virtual Learning Environment Adoption: A Case Study,” Turkish Online J. Educ. Technol., vol. 15, no. 1, pp. 69-81, 2016. 
[23] G. Hampel and K. Dancsházy, "Creating a Virtual Learning Environment,” J. Agric. Informatics ., vol. 5, no. 1, pp. 46-55, 2014.

[24] O. K. Kelvin, W. Gregory, and M. M. Samuel, "Integrating Virtual Worlds and Virtual Learning Environments in Schools in Developing Economies,” nternational J. Inf. Commun. Technol. Res., vol. 2, no. 1, pp. 17-21, 2012.

[25] J. Bush and F. Florida, "The Blended \& Virtual Learning FronTierr Special Report,” 2012.

[26] S. Chowdhry, S. Karolin, and A. Lourdes, "A Study of the Impact of Technology-Enhanced Learning on Student Academic Performance,” J. Perspect. Appl. Pract., vol. 2, no. 3, pp. 3-15, 2014.

[27] J. Biggs, Approaches to learning: Nature and measurement. The International Encyclopedia of Education, 1994.

[28] S. W. Y. Lee, “Investigating students' learning approaches, perceptions of online discussions, and students' online and academic performance.,” pp. 67-70 \& 344-353, 2013.

[29] "Romero, C., López, M. I., Luna, J. M., \& Ventura, S. (2013). Predicting students' final performance from participation in online discussion forums.," pp. 64-71, 455-476.

[30] C. K. Cheng, D. E. Paré, L. M. Collimore, and S. Joordens, "Assessing the effectiveness of a voluntary online discussion forum on improving students' course performance. Computers \& Education,.” pp. 55-57 \& 252-263, 2011.

[31] L. Wang, “Abstra act Introd uction,” World Libr. Inf. Congr., vol. 78th IFLA, pp. 1-15, 2012.
[32] L. A. Caudle, Using a Sociocultural Perspective to Establish Teaching and Social Presences Within a Hybrid Community of Mentor Teachers. Adult Learning,. 2013.

[33] M. Chakraborty and M. N. Fredrick, "Strategies for Virtual Learning Environments: Focusing on Teaching Presence and Teaching Immediacy,” J. internet Learn., vol. 4, no. 1, 2015.

[34] E. Kim, D. Nam, and J. L. Stimpert, "The Applicability of Porter?s Generic Strategies in the Digital Age: Assumptions, Conjectures, and Suggestions," J. Manage., vol. 30, no. 5, pp. 569-589, Oct. 2004.

[35] L. Nagel and T. G. Kotzé, "Supersizing e-learning: What a CoI survey reveals about teaching presence in a large online class.," Internet High. Educ., vol. 13(1), 2010.

[36] J. H. Wu, R. D. Tennyson, and T. L. Hsia, A study of student satisfaction in a blended e-learning system environment. 2010.

[37] Kember, D., McNaught, C., Chong, F. C. Y., Lam, P., \& Cheng, K. F. (2010). Understanding the ways in which design features of educational websites impact upon student learning outcomes in blended learning environments. Computers \& Education, 55, 1183-1192.

[38] P. Ginns and R. Ellis, "Quality in blended learning: Exploring the relationships between on-line and face-to-face teaching and learning," Internet High. Educ., vol. 10, no. 1, pp. 53-64, 2007.

[39] M. A. Ocak, "Why are faculty members not teaching blended courses? Insights from faculty members.” no. 56, pp. 689-699. 